\title{
CORONARY ARTERY BYPASS SURGERY AS TREATMENT FOR ISCHEMIC HEART FAILURE: THE PREDICTIVE VALUE OF VIABILITY ASSESSMENT WITH QUANTITATIVE POSITRON EMISSION TOMOGRAPHY FOR SYMPTOMATIC AND FUNCTIONAL OUTCOME
}

Domenico Pagano, FRCS ${ }^{\text {a }}$

Jonathan N. Townend, $\mathrm{MD}^{\mathrm{c}}$

William A. Littler, MD

Richard Horton, $\mathrm{MBChB}^{\mathrm{a}}$

Paolo G. Camici, MD, FACC ${ }^{\text {b }}$

Robert S. Bonser, FRCS ${ }^{\text {a }}$
Objectives: To determine the predictive value of quantitative evaluation of myocardial viability on changes in left ventricular function, exercise capacity, and quality of life after coronary artery bypass grafting in patients with ischemic heart failure (congestive heart failure, New York Heart Association class $\geq$ III) with and without angina. Methods: Thirty-five patients, 14 with congestive heart failure and angina (CHF-angina) and 21 with congestive heart failure without angina (CHF-no angina) were studied at baseline and 6 months after coronary bypass grafting. Left ventricular function was evaluated with transthoracic echocardiography and radionuclide ventriculography. Myocardial viability was assessed with $\left[{ }^{18} \mathrm{~F}\right]$-2-fluoro-2-deoxy-D-glucose using positron emission tomography. Peak aerobic capacity (peak oxygen consumption) and anaerobic threshold were assessed with treadmill exercise test and quality of life with a questionnaire. Results: A total of 286 of 336 dysfunctional left ventricular segments were viable. There were two perioperative deaths (5.7\%) and three late deaths. Left ventricular ejection fraction increased from $23 \% \pm 7 \%$ to $32 \% \pm 9 \%(p<0.0001)$, and a linear correlation was found between the number of viable segments and the changes in ejection fraction $(r=0.65 ; p=0.0001)$. Receiver operating characteristics curve identified eight viable segments as the best predictor for increase of ejection fraction more than 5 percentage points. Peak oxygen consumption increased from $15 \pm 4$ to $22 \pm 5 \mathrm{ml} / \mathrm{kg}$ per minute $(p<\mathbf{0 . 0 0 0 1})$. Preoperatively, anaerobic threshold was identified in one patient from the CHF-angina group and in all from the CHF-no angina group and increased from $13 \pm 4$ to $19 \pm 4 \mathrm{ml} / \mathrm{kg}$ per minute $(p<0.0001)$. Quality of life scores improved significantly in both groups. No correlation was found between the amount of viable dysfunctional myocardium and changes in exercise capacity or quality of life. Conclusions: In patients with postischemic congestive heart failure the amount of viable myocardium dictates the degree of improvement in left ventricular function after revascularization. (J Thorac Cardiovasc Surg 1998;115:791-9)
From the Cardiothoracic Surgical Unit ${ }^{\mathrm{a}}$ and University Department of Cardiovascular Medicine, ${ }^{\mathrm{c}}$ Queen Elizabeth Hospital, Birmingham, and MRC Cyclotron Unit and Royal Post-

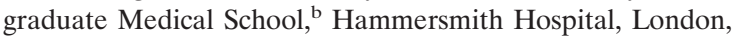
United Kingdom.

D. Pagano was supported by a Sheldon Clinical Research Fellowship of the West Midlands Health Authority, UK.

This paper was presented in part at the Sixty-ninth Meeting of the American Heart Association, New Orleans, La., 1996.

Received for publication July 11, 1997; revisions requested Oct. 13, 1997; revisions received Nov. 3, 1997; accepted for publication Nov. 6, 1997.

Address for reprints: Robert S. Bonser, MRCP, FRCS, Consultant Cardiothoracic Surgeon, Cardiothoracic Surgical Unit, Queen Elizabeth Hospital, Edgbaston, Birmingham B15 2TH, United Kingdom.

Copyright (C) 1998 by Mosby, Inc.

$0022-5223 / 98 \$ 5.00+0 \quad \mathbf{1 2 / 1 / 8 7 5 3 2}$ ongestive heart failure (CHF) affects $1 \%$ to $2 \%$ $U_{\text {of }}$ the adult population in industrialized countries $^{1}$ with high cost for health care organizations. The introduction of angiotensin converting enzyme (ACE) inhibitors achieved some improvement in prognosis, ${ }^{2}$ but the impact on exercise tolerance ${ }^{3}$ and quality of life ${ }^{4}$ has been limited.

Coronary artery disease (CAD) is the most common cause of $\mathrm{CHF}^{5}$ and is associated with a worse prognosis than other causes. ${ }^{6}$ However, in patients with CAD, impairment of left ventricular (LV) function is not always irreversible. Dysfunctional myocardial segments subtended by stenotic coronary arteries may recover contractile function after revascularization and the presence of this "hibernating" myocardium ${ }^{7}$ can be predicted by noninvasive 
Table I. Characteristics of study patients

\begin{tabular}{|c|c|c|c|c|c|c|c|c|c|c|c|c|c|}
\hline \multicolumn{10}{|c|}{ Baseline } & \multicolumn{4}{|c|}{ Follow-up } \\
\hline Patient & Age & Sex & Symptoms & NYHA & $C C S$ & LVEF (\%) & $D S$ & $V D S$ & $\mathrm{PVO}_{2}{ }^{*}$ & NYHA & $C C S$ & LVEF (\%) & $\mathrm{PVO}_{2}{ }^{*}$ \\
\hline 1 & 49 & $\mathrm{M}$ & $\mathrm{HF}$ & 4 & & 17 & 14 & 14 & $13.3^{*}$ & 1 & & 24 & $21.5^{*}$ \\
\hline 2 & 57 & M & $\mathrm{HF}$ & 3 & & 23 & 15 & 13 & $21^{*}$ & 1 & & 38 & $16^{*}$ \\
\hline 3 & 54 & M & $\mathrm{HF}$ & 3 & & 30 & 10 & 9 & $15.4^{*}$ & 1 & & 42 & $24.4^{*}$ \\
\hline 4 & 59 & M & $\mathrm{HF}$ & 3 & & 26 & 15 & 15 & $17^{*}$ & 1 & & 56 & $35^{*}$ \\
\hline 5 & 66 & M & $\mathrm{HF}$ & 4 & & 21 & 11 & 11 & - & 2 & & 32 & - \\
\hline 6 & 50 & M & $\mathrm{HF}$ & 3 & & 37 & 10 & 6 & $16.7^{*}$ & 1 & & 38 & $19.2^{*}$ \\
\hline 7 & 50 & M & $\mathrm{HF}$ & 4 & & 30 & 13 & 13 & $20.9^{*}$ & 2 & & 41 & $23.7^{*}$ \\
\hline 8 & 68 & M & $\mathrm{HF}$ & 3 & & 15 & 7 & 7 & $12.2^{*}$ & 1 & & 21 & $27.8^{*}$ \\
\hline 9 & 50 & M & $\mathrm{HF}$ & 3 & & 21 & 13 & 13 & $12.3^{*}$ & 2 & & 23 & $20.2^{*}$ \\
\hline 10 & 48 & M & $\mathrm{HF}$ & 4 & & 19 & 10 & 9 & $12.1^{*}$ & 2 & & 25 & $19^{*}$ \\
\hline 11 & 65 & $\mathrm{~F}$ & $\mathrm{HF}$ & 3 & & 37 & 9 & 8 & $7.4^{*}$ & 2 & & 40 & $18.4^{*}$ \\
\hline 12 & 63 & M & $\mathrm{HF}$ & 3 & & 20 & 12 & 12 & $17.2^{*}$ & 1 & & 28 & $19^{*}$ \\
\hline 13 & 57 & M & $\mathrm{HF}$ & 3 & & 22 & 14 & 13 & $7.3^{*}$ & 1 & & 37 & $18^{*}$ \\
\hline 14 & 66 & M & $\mathrm{HF}$ & 3 & & 21 & 7 & 7 & $20^{*}$ & 2 & & 25 & $17^{*}$ \\
\hline 15 & 72 & $\mathrm{~F}$ & $\mathrm{HF}$ & 3 & & 19 & 16 & 15 & $13.3^{*}$ & 2 & & 26 & $15.5^{*}$ \\
\hline 16 & 57 & M & $\mathrm{HF}$ & 3 & & 25 & 14 & 14 & $12.8^{*}$ & 2 & & - & $17.3^{*}$ \\
\hline 17 & 62 & M & $\mathrm{HF}$ & 4 & & 10 & 13 & 13 & $6.4^{*}$ & 1 & & 29 & $20.7^{*}$ \\
\hline 18 & 66 & M & $\mathrm{HF}$ & 3 & & 22 & 15 & 15 & $22 *$ & 1 & & 36 & $24 *$ \\
\hline 19 & 65 & M & $\mathrm{HF}$ & 3 & & 18 & 15 & 12 & $9.7^{*}$ & 2 & & 24 & $21.7^{*}$ \\
\hline 20 & 59 & M & $\mathrm{HF}$ & 3 & & 26 & 15 & 14 & $15^{*}$ & 1 & & 38 & $23.5^{*}$ \\
\hline 21 & 59 & M & $\mathrm{HF}$ & 3 & & 25 & 9 & 8 & $12.7^{*}$ & 1 & & 39 & $20.7^{*}$ \\
\hline 22 & 41 & $\mathrm{~F}$ & $\mathrm{~A}+\mathrm{HF}$ & 3 & 2 & 37 & 12 & 5 & 15 & 1 & 1 & 29 & $21^{*}$ \\
\hline 23 & 55 & $\mathrm{~F}$ & $\mathrm{~A}+\mathrm{HF}$ & 3 & 3 & 27 & 10 & 10 & $21.8^{*}$ & 2 & 2 & 29 & $37 *$ \\
\hline 24 & 68 & M & $\mathrm{A}+\mathrm{HF}$ & 3 & 2 & 25 & 9 & 4 & 10 & 2 & 1 & 18 & $20.5^{*}$ \\
\hline 25 & 45 & M & $\mathrm{A}+\mathrm{HF}$ & 3 & 2 & 32 & 9 & 9 & 19.3 & 1 & 1 & 54 & $22.6^{*}$ \\
\hline 26 & 53 & M & $\mathrm{A}+\mathrm{HF}$ & 3 & 2 & 35 & 4 & 0 & 19.5 & 1 & 1 & 35 & $33^{*}$ \\
\hline 27 & 65 & M & $\mathrm{A}+\mathrm{HF}$ & 3 & 3 & 23 & 12 & 0 & 18.3 & 2 & 1 & 22 & $22.4^{*}$ \\
\hline 28 & 63 & M & $\mathrm{A}+\mathrm{HF}$ & 3 & 2 & 20 & 10 & 10 & 17.7 & 1 & 1 & 25 & $15^{*}$ \\
\hline 29 & 48 & M & $\mathrm{A}+\mathrm{HF}$ & 3 & 2 & 32 & 7 & 4 & 14.3 & 1 & 1 & 33 & $26^{*}$ \\
\hline 30 & 49 & M & $\mathrm{A}+\mathrm{HF}$ & 3 & 3 & 35 & 7 & 3 & 14.5 & 1 & 1 & 36 & $22^{*}$ \\
\hline 31 & 62 & M & $\mathrm{A}+\mathrm{HF}$ & 4 & 3 & 14 & 12 & 0 & 17 & - & - & - & - \\
\hline 32 & 70 & M & $\mathrm{A}+\mathrm{HF}$ & 4 & 3 & 15 & 13 & 13 & 12 & - & - & - & - \\
\hline 33 & 59 & M & $\mathrm{A}+\mathrm{HF}$ & 3 & 2 & 20 & 9 & 4 & 17.5 & - & - & - & - \\
\hline 34 & 62 & M & $\mathrm{A}+\mathrm{HF}$ & 3 & 2 & 14 & 13 & 6 & 11 & - & - & - & - \\
\hline 35 & 59 & M & $\mathrm{A}+\mathrm{HF}$ & 3 & 3 & 15 & 14 & 0 & 12 & - & - & - & - \\
\hline
\end{tabular}

$M$, Male; $F$, female; $A$, angina; $H F$, heart failure; $N Y H A$, New York Health Association class; $C C S$, Canadian Cardiovascular Society angina class; $D S$, dysfunctional segments; $V D S$, viable dysfunctional segments; $\mathrm{PVO}_{2}$, Peak $\mathrm{VO}_{2}\left({ }^{*}\right)$ : Anaerobic threshold attained; $L V E F$, left ventricular ejection fraction.

techniques such as positron emission tomography (PET), thallium-201 scintigraphy, and dobutamine echocardiography. ${ }^{8}$ The phenomenon of myocardial hibernation raises the possibility that patients with $\mathrm{CAD}$ and CHF may gain functional and prognostic benefit from coronary artery bypass grafting $(\mathrm{CABG})$. Although the randomized trials of coronary artery surgery and registry data demonstrated the symptomatic and prognostic benefit of $\mathrm{CABG}$ in patients with angina or exercise-induced ischemia, ${ }^{9,}{ }^{10}$ registry data suggested no prognostic benefit of surgery in patients with predominant symptoms of heart failure. ${ }^{9}$ More recently, it has been shown that surgical revascularization of hibernating myocardium can result in improved ejection fraction
(EF) even in patients with severe impairment of LV function. ${ }^{11,12}$ In the absence of angina or exerciseinduced ischemia, selection of patients in whom ventricular function is most likely to improve after CABG remains difficult, and the effect of revascularization on the clinical status and functional capacity of patients with $\mathrm{CHF}$ is unclear. In these patients the amount of viable myocardium necessary to produce clinically meaningful improvements in LV function and symptomatic status after CABG to balance the known high operative risk is not known.

The aim of this study was to determine the predictive value of quantitative evaluation of myocardial viability on changes in ventricular function, exercise capacity, and quality of life after $\mathrm{CABG}$ in 


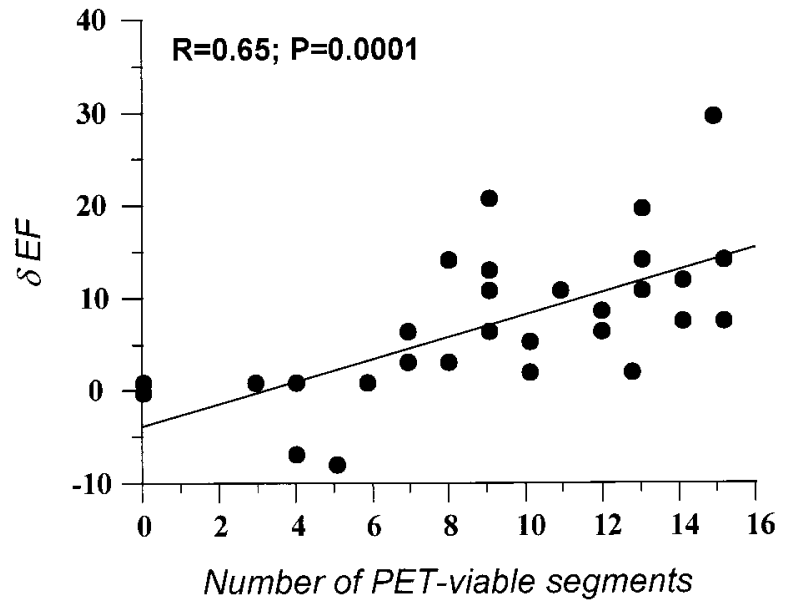

Fig. 1. Correlation between the number of viable dysfunctional LV segments and the absolute changes in LVEF $(\delta-E F)$. The equation for this relationship is $\mathrm{Y}=$ $1.2 \mathrm{X}+-3.97$.

a group of patients with CAD and clinical heart failure with and without angina.

\section{Methods}

Patient population. The patients for this study were recruited from those referred to our hospital for investigation of heart failure or consideration for CABG or heart transplantation. Inclusion criteria were chronic $(\geq 6$ months) heart failure (New York Heart Association [NYHA] class $\geq$ III), sinus rhythm, multivessel CAD, impaired LV systolic function, with at least one dysfunctional LV wall subtended by a stenotic coronary artery amenable to operative revascularization. Exclusion criteria were myocardial infarction within 6 months, decompensation of heart failure within 3 months, the presence of more than moderate mitral valve regurgitation as assessed by transthoracic echocardiography, and the presence of LV aneurysm. Over an 18-month period 39 consecutive patients ( 35 male and 4 female, mean age $58 \pm 7$ years; range 41 to 72 years) met the entry criteria. On the basis of the patients' limiting symptoms and the findings of the treadmill exercise test, two groups were identified: $C H F$ angina-14 patients with symptoms of heart failure and effort angina; $C H F-n o$-angina-25 patients with symptoms of heart failure but no angina. CABG was performed in all the 14 patients from the CHF-angina group irrespective of the viability study findings and in 21 of 25 patients from the CHF-no-angina group. Four patients in the latter group, in whom no evidence of viability could be demonstrated by PET, did not undergo CABG and underwent cardiac transplantation or continued medical treatment. Thus 35 patients constitute the population of this study (Table I).

All 35 patients had experienced at least one myocardial infarction (range 1 to 3 ), and the mean time of the most recent was $30 \pm 14$ months (range 12 to 60 months) before the study period. Eleven patients had diabetes (four had

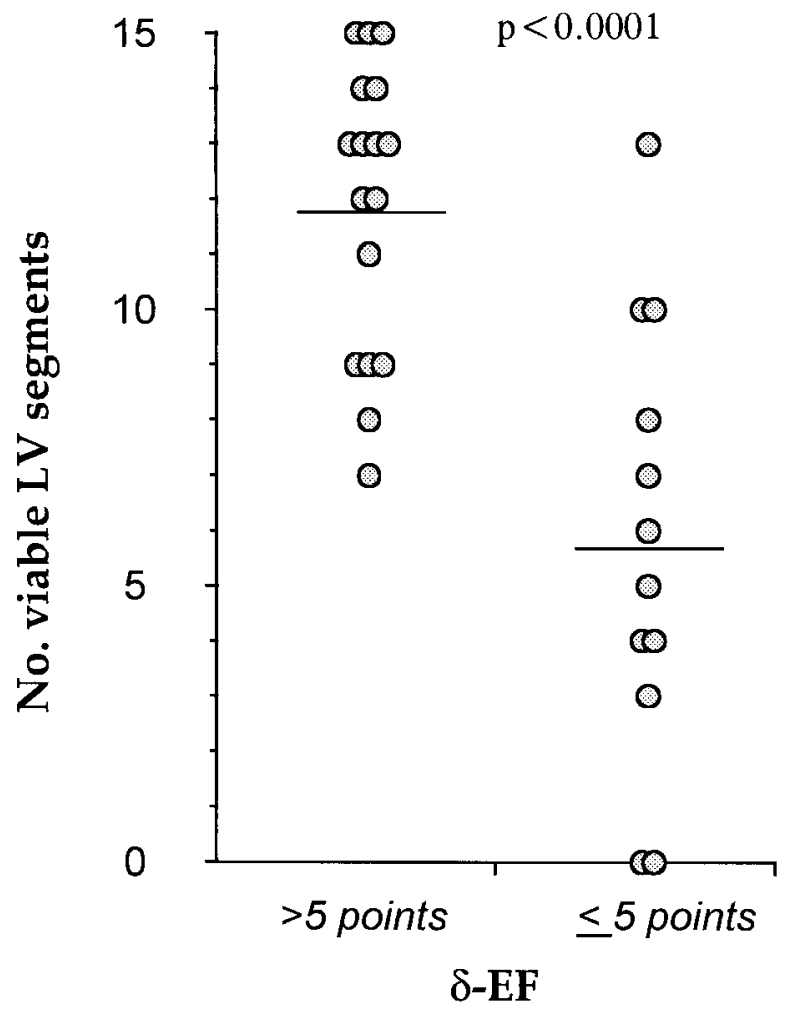

Fig. 2. Comparison of number of viable dysfunctional LV segments in patients with changes in LVEF $(\delta-E F)>5$ percentage points and those with $\leq 5$ percentage points or deterioration.

insulin-dependent diabetes), and five patients had a history of hypertension. The preoperative electrocardiogram (ECG) showed Q-wave infarction in at least one myocardial territory in all the patients (two territories in nine patients). All patients were receiving maximal medical therapy for heart failure, including ACE inhibitors (35), diuretics (25), and digoxin (7) at the time of recruitment. The patients from the CHF-angina group were also receiving antianginal treatment, including nitrates (14) and calcium channel blockers (3). One patient had a permanent pacemaker but was in sinus rhythm at the time of recruitment (patient 16, Table I).

The study was approved by the local ethics committee and written informed consent was obtained from all the patients before the study. The radiation exposure was licensed by the UK Administration of Radioactive Substances Advisory Committee.

Study protocol. Selective coronary arteriography was performed in all patients. Patients underwent cardiopulmonary exercise testing, echocardiography, PET imaging with $\left[{ }^{18} \mathrm{~F}\right]$-2-fluoro-2-deoxy-D-glucose (FDG) and radionuclide ventriculography (MUGA) within 4 weeks before CABG. Echocardiography, MUGA scanning, and treadmill exercise testing were repeated 6 months after the operations. Quality of life was assessed by a self-administered questionnaire before and 6 months after operation. 


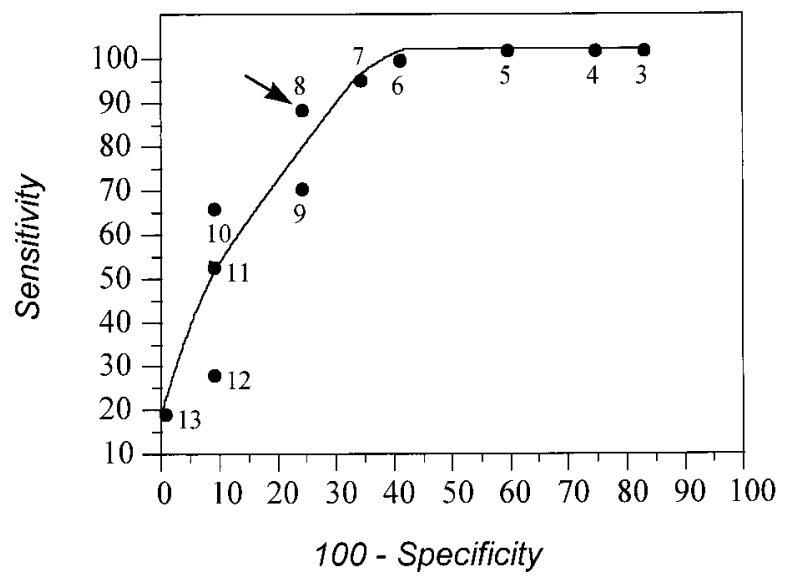

Fig. 3. ROC curve demonstrating the sensitivity-specificity pairs for the number of PET-viable segments required to obtain improvements in LVEF greater than 5 percentage points after $\mathrm{CABG}$. The arrow indicates the operator point associated with the best tradeoff between sensitivity $(88 \%)$ and specificity $(75 \%)$. The area fitted under the curve is $75 \%$ (trapezoid rule).

All medical therapy with the exclusion of nitrates was withdrawn on the study day both at baseline and followup.

Cardiopulmonary exercise testing. Symptom-limited cardiopulmonary exercise test was performed using a treadmill according to a modified Naughton protocol. Breath-by-breath ventilatory and gas exchange data were measured using a Morgan Benchmark system (PK Morgan Ltd, Gillingham, UK). Peak oxygen consumption $\left(\mathrm{VO}_{2}\right)$ was calculated as the mean of the values recorded during 30 seconds before peak exercise. ${ }^{13}$ Attainment of the anaerobic threshold was assessed as the point at which carbon dioxide $\left(\mathrm{VCO}_{2}\right)$ increases disproportionately to $\mathrm{VO}_{2}$ (v-slope method). ${ }^{14}$ The respiratory exchange ratio at peak exercise was calculated as the ratio $\mathrm{VCO}_{2} / \mathrm{VO}_{2}$. Exercise tests were supervised by a physician unaware of the patients' clinical details to avoid bias.

Echocardiography. Segmental LV wall motion was assessed by transthoracic echocardiography (HP Sonos 2500, Hewlett-Packard Company, Andover, Mass.) according to the recommendations of the American Society of Echocardiography. ${ }^{15}$ To circumvent the problem of postoperative paradoxical septal movement, wall thickening was primarily used for the assessment of septal segments. The wall motion was graded as 1 (normal), 2 (hypokinetic), 3 (akinetic), and 4 (dyskinetic). The wall motion score index (WMSI) was calculated as the sum of the scores of the left ventricular segments divided by the number of segments evaluated. ${ }^{15} \mathrm{~A}$ segment was considered recovering contractile function after $\mathrm{CABG}$ if there was a reduction of at least one point in the wall motion/ systolic thickening score. The echo images were analyzed by two independent observers blinded to the clinical details and viability details of the patients. In a random subset of 10 patients (160 segments), the interobserver and the intraobserver agreement was assessed using the kappa agreement test: interobserver $\kappa=0.82(95 \%$ confidence interval 0.69 to 0.95 ); intraobserver $\kappa=0.90$ ( $95 \%$ confidence interval 0.80 to 1.00 ).

PET. The study for the measurement of myocardial glucose uptake was carried out during hyperinsulinemic euglycemic clamp with the glucose analog FDG as described previously. ${ }^{16}$ Images were resliced in the short axis view, and the LV was divided to provide 16 regions of interest comparable to the ones used for echocardiographic analysis. ${ }^{15}$ A dysfunctional segment was considered viable if FDG uptake was $\geq 0.25 \mu \mathrm{mol} / \mathrm{min}$ per gram. ${ }^{17}$

MUGA. All patients underwent radionuclide ventriculography for the assessment of LVEF. ${ }^{16}$ Analysis was performed by two independent physicians blinded to clinical details including the preoperative or postoperative status. The interobserver and intraobserver agreement was assessed in a random subset of 10 patients by means of a standard method. ${ }^{18}$ The mean of the differences in EF was $0.05 \pm 1.5$ percentage points and the $95 \%$ limits of agreement were $-2.9 \%$ to $3 \%$. An improvement in LVEF $>5$ percentage points (recognized variability in calculating EF with MUGA) was considered significant.

Quality of life assessment. Quality of life was assessed with the self-administered Minnesota Living with Heart Failure Questionnaire, ${ }^{4}$ which assesses the patient's perception of how his or her emotional and physical status is impaired by heart failure. Increasing scores relate to the severity of impairment, the maximum total score being 105. The physical and emotional impact of heart failure can also be deduced. ${ }^{19}$ The baseline reliability of the questionnaire was assessed by a second self-administration after an interim period of 7 to 14 days and the agreement between baseline scores was 0.90 (95\% confidence interval 0.86 to 0.95 ) (weighted kappa).

CABG. Surgery was performed by one surgeon (R.S.B.) By use of cardiopulmonary bypass, mild hypothermia $\left(32^{\circ}\right.$ to $34^{\circ} \mathrm{C}$ ), and intermittent ischemic arrest.

Statistical analysis. Continuous data are expressed as mean \pm 1 standard deviation. Comparison of paired data was made with paired $t$ test. Categorical data were compared with the $\chi^{2}$ or Fisher's exact test as appropriate. Simple linear regression analysis with Pearson's correlation coefficient was performed to investigate the relationship between two continuous variables. The univariate association between death and the potential predictors was assessed with the Fisher's exact test, unpaired $t$ test, or Mann-Whitney U test as appropriate and with univariate logistic regression. Stepwise logistic regression was then performed, including predictors with $p$ values not greater than 0.05 in the univariate analysis, and keeping predictors with $p$ values not greater than 0.05 in the multivariate model. Receiver operator characteristics (ROC) curve was derived according to the method described by Metz. ${ }^{20}$ The univariate association between the improvement in LVEF in excess of 5 percentage points and the potential predictors was assessed with Fisher's exact test.

\section{Results}

Surgery and clinical outcome. The mean number of grafts per patient was three and all received a left 
internal thoracic artery graft to the left anterior descending coronary artery. The mean cardiopulmonary bypass time was $50 \pm 16$ minutes (range 12 to 88 minutes), and the mean aortic crossclamp time was $24 \pm 7$ minutes (range 6 to 39 minutes). There were two deaths (patients $n=31$ and $n=32$, Table I) caused by myocardial failure during the perioperative period (overall perioperative/30 day mortality $5.7 \%$ ). In the remaining patients there was no evidence of new myocardial infarction according to clinical and electrocardiogram (ECG) criteria. Two patients received inotropic support, and one patient required intraaortic balloon counterpulsation after operation. The mean intensive care unit stay was $1.5 \pm 1.3$ days (range 1 to 5 days). Two patients $(5.7 \%)$ had transient neurologic dysfunction develop, which resolved without long-term sequelae. Three patients had postoperative atrial fibrillation develop requiring direct-current cardioversion, which resulted in restoration of sinus rhythm. The medical therapy for heart failure was maintained unchanged throughout the study period with the exception of diuretics, the dose of which was reduced in eight patients. Antianginal medications (nitrates and calcium-channel blockers) were withdrawn at the time of $\mathrm{CABG}$, and no patient required antianginal treatment after CABG. No patient attended cardiac rehabilitation before the follow-up investigations. There were three late sudden deaths before the follow-up study at 2, 3, and 3 months postoperatively (patients 33, 34, and 35, Table I). Death occurred out of the hospital, and no postmortem examination was performed. The remaining 30 patients underwent a follow-up study 6 months after CABG. One patient required hospital admission 4 weeks after $\mathrm{CABG}$ for exacerbation of heart failure symptoms caused by atrial fibrillation; elective direct-current cardioversion was done and long-term treatment with amiodarone was prescribed. The NYHA class and the Canadian Cardiovascular Society angina class improved in all patients (Table I).

Factors predictive of mortality. Five deaths occurred in the study group (two perioperative and three before follow-up study); thus the 6-month actuarial survival was $86 \%$. Univariate analysis identified low LVEF $(p=0.002)$, small number of dysfunctional viable segments $(p=0.02)$, and low percentage of viable dysfunctional myocardium (number viable dysfunctional/total number dysfunctional segments $\times 100)(p=0.02)$ as factors associated with early death (perioperative and before follow-up), whereas age, sex, NYHA class, peak
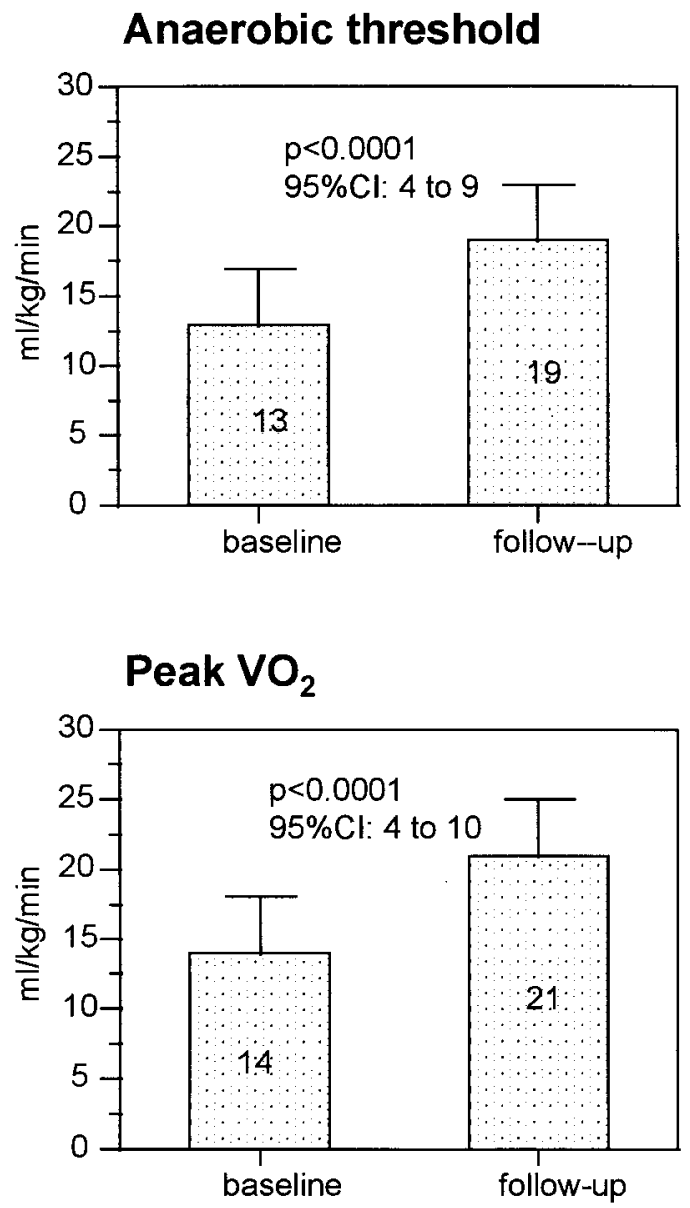

\section{Exercise time}

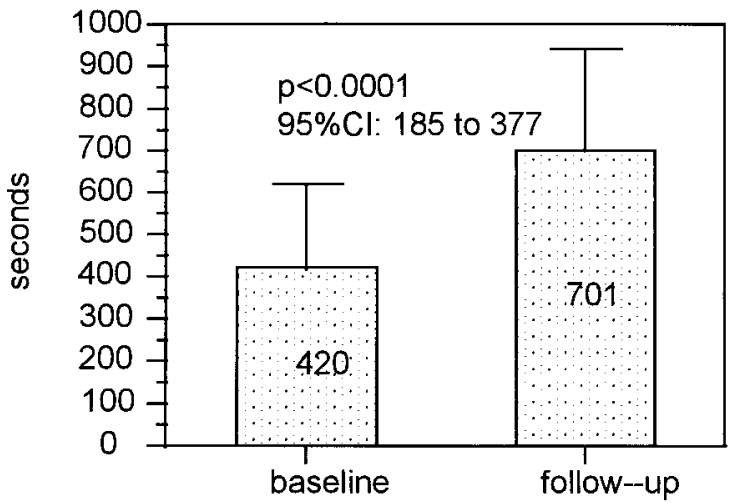

Fig. 4. Exercise data for $\mathrm{CHF}-$ no-angina patients. Anaerobic threshold was achieved in all cases at baseline and at the follow-up study. The respiratory exchange ratio at peak exercise before CABG was $1.12 \pm 0.07$ and $1.1 \pm$ 0.07 at follow-up. Heart rate at peak exercise was $129 \pm 29$ beats/min before CABG and $137 \pm 18$ beats $/ \mathrm{min}$ at follow-up $(p=0.09) .95 \% \mathrm{CI}=95 \%$ confidence interval of the mean change. 
Table II. Exercise test data on all and CHF-angina patients

\begin{tabular}{|c|c|c|c|c|c|c|c|c|}
\hline & \multicolumn{4}{|c|}{ All patients } & \multicolumn{4}{|c|}{ CHF-angina patients } \\
\hline & Baseline & Follow-up & $95 \% C I$ & $p$ Value & Baseline & Follow-up & $95 \% C I$ & $p$ Value \\
\hline Peak $\mathrm{VO}_{2}(\mathrm{ml} / \mathrm{kg} / \mathrm{min})$ & $15 \pm 4$ & $22 \pm 5$ & 4.9-9.3 & $<0.0001$ & $16 \pm 4$ & $24 \pm 5$ & $3.3-12$ & $<0.0001$ \\
\hline Exercise time (sec) & $439 \pm 215$ & $718 \pm 227$ & 204-354 & $<0.0001$ & $480 \pm 215$ & $756 \pm 195$ & $133-419$ & $<0.0001$ \\
\hline Heart rate (peak exercise) bpm & $126 \pm 20$ & $141 \pm 16$ & 6-22 & 0.0008 & $118 \pm 15$ & $143 \pm 10$ & 9-39 & 0.003 \\
\hline
\end{tabular}

$95 \%$ CI, 95\% Confidence interval of the mean change.

$\mathrm{VO}_{2}$, and exercise time were not predictive. Stepwise logistic regression identified low LVEF $(p=0.03)$ and low percentage of viable dysfunctional myocardium ( $p=0.03)$ equally as predictors of early death.

Myocardial viability. A total of $453 \mathrm{LV}$ segments could be assessed by both echocardiography and PET, and $425(94 \%)$ of these were revascularized. Of these, $89(21 \%)$ had normal wall motion and 336 (79\%) were dysfunctional (180 hypokinetic and 156 akinetic). The mean number of dysfunctional segments per patient was $11 \pm 3$ (range 7 to 15 ). The FDG uptake was significantly higher in the hypokinetic than in the akinetic segments $(0.43 \pm 0.16$ vs $0.38 \pm 0.15 \mu \mathrm{mol} / \mathrm{min}$ per gram; $p=0.003)$. A total of $286(85 \%)$ dysfunctional segments were PET viable (i.e., had FDG uptake $\geq 0.25 \mu \mathrm{mol} / \mathrm{min}$ per gram). Viability was detected in 167 of 180 (93\%) hypokinetic and in 123 of 156 (79\%) akinetic segments $(p=0.004)$. The mean number of PET viable segments per patient was $9 \pm 4$ (range 0 to 15 ). Of these, 190 out of 286 segments (90 hypokinetic and 100 akinetic) had improved wall motion after CABG (positive predictive value 66\%). Forty-eight of the 50 dysfunctional segments that were deemed nonviable (FDG uptake $\leq 0.25 \mu \mathrm{mol} / \mathrm{min}$ per gram) did not have improved wall motion after operation (negative predictive value $96 \%$ ). In 12 out of 425 revascularized segments (9 normal and 3 dysfunctional) $(2.5 \%)$ wall motion worsened after CABG. The percentage of PET viable myocardium was less in the CHF-angina group (45 of 80 [56\%] dysfunctional segments) than in the CHF-no angina group (241 of 257 [94\%]).

Changes in $\mathbf{L V}$ function. The mean baseline radionuclide LVEF was $23 \% \pm 7 \%$. The patient with a pacemaker (patient 16, Table I) was excluded from the follow-up radionuclide ventriculography because during this study he manifested a predominant ventricular paced rhythm. In the remaining 29 patients there was a significant increase in mean LVEF to $32 \% \pm 9 \%(95 \%$ confidence interval of the change $4.3 \%$ to $11 \%$; $p<0.0001)$ after revascularization. LVEF changed from $29 \% \pm 6 \%$ to $31 \%$ $\pm 10 \%(p=0.58)$ in the CHF-angina group and from $23 \% \pm 7 \%$ to $33 \% \pm 8 \%(p<0.0001)$ in the $\mathrm{CHF}-$ no angina group. There was a significant reduction in the mean WMSI from $2.18 \pm 0.3$ to $1.7 \pm 0.3(95 \%$ confidence interval of the mean change: -0.6 to $-0.3 ; p<0.0001)$, and a linear correlation was found between the reduction (improvement) in WMSI and EF changes $(r=-71, p<$ 0.0001). A linear correlation was found between the number of dysfunctional segments with FDG uptake $\geq 0.25 \mu \mathrm{mol} / \mathrm{min}$ per gram in each patient (PET-viable segments) and the changes in EF (Fig. 1). The 17 patients with $\mathrm{EF}$ improvement $>5$ percentage points had more dysfunctional viable segments compared with the 12 patients with less or no improvement (Fig. 2). ROC analysis identified eight viable segments as the discriminator to identify $>5$ percentage points improvement in EF (Fig. 3).

Changes in exercise capacity. One patient with left main $\mathrm{CAD}$ did not undergo preoperative exercise testing (patient 5, Table I). In CHF-angina patients exercise was discontinued because of a combination of chest pain and dyspnea and in those from the $\mathrm{CHF}$-no angina group because of dyspnea and fatigue without ECG evidence of ischemia. An anaerobic threshold was identified in all 20 patients from CHF-no angina and in 1 of 9 patients from CHF-angina group. The exercise data are shown in Table II and Fig. 4. The number of viable dysfunctional segments and the changes in LVEF did not correlate with any exercise parameters.

Quality of life scores. Quality of life scores improved in all the patients (Table III).

\section{Discussion}

In this study, the amount of viable dysfunctional myocardium predicted the extent of LV functional improvement in patients with $\mathrm{CHF}$ after CABG. Objective improvements in exercise performance and quality of life scores occurred but did not correlate with the amount of viable dysfunctional myocardium. The presence of angina was not always 
Table III. Quality of life scores

\begin{tabular}{|c|c|c|c|c|c|c|c|c|c|}
\hline & \multicolumn{3}{|c|}{ All patients } & \multicolumn{3}{|c|}{ CHF-angina patients } & \multicolumn{3}{|c|}{ CHF-no-angina patients } \\
\hline & Baseline & Follow-up & $p$ Value & Baseline & Follow-up & $p$ Value & Baseline & Follow-up & $p$ Value \\
\hline MLHF & $57 \pm 15$ & $30 \pm 11$ & $<0.0001$ & $51 \pm 4$ & $34 \pm 6$ & 0.001 & $59 \pm 16$ & $29 \pm 12$ & $<0.0001$ \\
\hline Physical & $26 \pm 5$ & $14 \pm 7$ & $<0.0001$ & $22 \pm 2$ & $15 \pm 2$ & $<0.0001$ & $27 \pm 5$ & $14 \pm 7$ & $<0.0001$ \\
\hline Emotional & $13 \pm 5$ & $7 \pm 3$ & 0.0001 & $10 \pm 2$ & $6 \pm 1$ & 0.01 & $14 \pm 5$ & $7 \pm 3$ & $<0.0001$ \\
\hline
\end{tabular}

$M L H F$, Minnesota Living with Heart Failure questionnaire; Scores are for the entire questionnaire and for the physical and emotional dimensions.

associated with viability but lack of angina did not preclude objective improvements in LVEF or exercise tolerance. The relief of angina after CABG improved exercise tolerance irrespective of the amount of viable myocardium.

Mortality. Severity of LV dysfunction is known to influence the early outcome of CABG particularly if advanced heart failure is present. ${ }^{21}$ Although recent studies have shown low mortality in patients with low EF undergoing CABG, most patients studied had angina without heart failure. ${ }^{22,23}$ This study suggests that the extent of viable dysfunctional myocardium is an important predictor of early death after CABG when heart failure is present. If this finding is reproduced in a larger population, the assessment of viability becomes critical in the evaluation of the risk/benefit ratio when considering operation.

Viability and angina. Significant myocardial viability was detected both in patients with and without angina, but this symptom was an unreliable predictor of viability. It is known that there is no correlation between the presence of angina and the severity and extent of CAD or ischemia. ${ }^{24}$ Viability was greater in the CHF-no angina group, but a meaningful comparison of the two groups could not be made because we did not submit patients with no viability and no angina to $\mathrm{CABG}$. Although there was differential recovery of function between groups, the denominator is small, precluding meaningful comparisons.

LV function. LV functional recovery was related to the amount of viability. The positive predictive accuracy of PET imaging for regional LV functional recovery $(66 \%)$ was lower than previously reported in patients with modest LV impairment ${ }^{25}$ but comparable to studies of patients with severe LV dysfunction. ${ }^{11}$ The reduced accuracy in such patients may reflect the amount of akinetic segments ( $46 \%$ in our study) because these may have more advanced ultrastructural changes than less dysfunctional regions. ${ }^{26}$ It is possible that such segments require more time for functional recovery ${ }^{27}$ and our single 6 months assessment may have underestimated the amount of improvement. In addition, islands of myocytes in myocardium with significant subendocardial scarring may be viable but with little prospect of improving resting contractile function after CABG.$^{28}$ However, these regions may still improve on inotropic stimulation and contribute to LV function on exercise. ${ }^{29}$ In agreement with a previous study, ${ }^{11}$ an improvement in LVEF of greater than 5 percentage points occurred only in patients with significant viable myocardium. This underlines the importance of accurate preoperative assessment of viability particularly in patients with very poor LV function who have the highest perioperative risk.

Exercise performance. Objective measures of exercise performance improved in all the patients after CABG. In the CHF-angina patients, however, failure to attain anaerobic threshold and the limitation of exercise by angina do not allow an objective evaluation of the results. In contrast, all the patients limited by heart failure symptoms exercised maximally attaining anaerobic threshold and improved markedly.

No correlation was found between the changes in LVEF, viability, and exercise parameters in accordance with other studies, ${ }^{30}$ and this requires explanation. No data are available relating viability to $\mathrm{LV}$ function during exercise. We have previously observed in a similar cohort of patients that $\mathrm{CABG}$ may be associated with improvement in peak $\mathrm{VO}_{2}$ and LV inotropic contractile reserve without change in resting LV function. ${ }^{31}$ Finally, the improvement in global LV function during exercise may depend not only on the recruitment of dysfunctional myocardium but also on the relief of exercise-inducible ischemia in normofunctioning segments.

Quality of life scores. The Minnesota Living with Heart Failure Questionnaire scores improved in all the patients. However, whereas in the patients with angina improvements in quality of life may be secondary to relief of chest pain, the improvements in the heart failure patients reflect a genuine improvement in heart failure functional status. 
CABG for congestive cardiac failure. An important observation of this study was the assessment of the effects of CABG in patients with postischemic cardiomyopathy with no symptoms of angina but viable dysfunctional myocardium. In these patients improvements in LV function, exercise capacity, and quality of life scores were substantial and clearly superior to those usually obtained by medical treatment. ${ }^{3,4}$ To date, CABG has been used mostly to treat patients with angina or demonstrable ischemia. The results of this study suggest that CABG may also have a role in the treatment of severe heart failure in patients with CAD even in the absence of angina. Both angina and hibernation are manifestations of ischemia, ${ }^{16}$ thus it is not surprising that coronary revascularization is effective in improving both conditions. $\mathrm{LV}$ function and peak $\mathrm{VO}_{2}$ are powerful prognostic indicators in heart failure, ${ }^{13}$ and it is possible that the improvements demonstrated 6 months after CABG may translate into prognostic benefit.

Study limitations. We did not compare the effects of operation with those of continued medical treatment. Although some retrospective studies ${ }^{9,22}$ have attempted this, no study has a truly randomized control group and most of the patients treated in the operated group had angina as a predominant symptom. In this study all the patients in the CHF-no angina group had extensive myocardial viability, and this may be a reflection of the selection criteria. The role of operation in the management of patients in the CHF-no angina group with minimal or absent viable myocardium remains unknown. The results of this study are encouraging but need corroboration in a larger population.

We acknowledge the help and support of medical and technical colleagues at the Queen Elizabeth Hospital, Birmingham, and the MRC-Cyclotron Unit Hammersmith Hospital, London, who contributed to data acquisition. We are indebted to P. Davies, PhD C.Stat, from the school of Mathematics and Statistics of the University of Birmingham for the advice in the statistical analysis of the data.

\section{REFERENCES}

1. Kannel W, Belanger A. Epidemiology of heart failure. Am Heart J 1991;121:951-7.

2. CONSENSUS study group. Effects of enalapril on mortality in severe congestive heart failure: results of the Cooperative North Scandinavian Enalapril Survival Study. N Engl J Med 1987;316:1429-35.

3. Cohn J, Johnson G, Ziesche S, et al. A comparison of enalapril with hydralazine-isosorbide dinitrate in the treat- ment of chronic congestive heart failure. N Engl J Med 1991;325:303-10.

4. Rector T, Johnson G, Dunkman B, et al. Evaluation by patients with heart failure of the effects of enalapril compared with hydralazine plus isosorbide dinitrate on quality of life. V-HeFT II. Circulation 1993;87(suppl VI):VI-71-7.

5. SOLVD Investigators. Effect of enalapril on survival in patients with reduced left ventricular ejection fraction and congestive heart failure. N Engl J Med 1991;325:293-302.

6. Jessup Likoff M, Chandler S, Kay H. Clinical determinants of mortality in chronic congestive heart failure secondary to idiopathic dilated or to ischaemic cardiomyopathy. Am J Cardiol 1987;59:634-8.

7. Rahimtoola SH. The hibernating myocardium. Am Heart J 1989;117:211-21.

8. Dilsizian V, Bonow RO. Current diagnostic techniques of assessing myocardial viability in patients with hibernating and stunned myocardium. Circulation 1993;87:1-20.

9. Alderman E, Fisher L, Litwin P, et al. Results of coronary artery surgery in patients with poor left ventricular function (CASS). Circulation 1983;4:785-95.

10. Passamani E, Davies K, Gillespie M, et al. A randomised trial of coronary artery bypass surgery: survival of patients with low ejection fraction. N Engl J Med 1985;312:1665-71.

11. vom Dahl J, Eitzman DT, al Aouar ZR, et al. Relation of regional function, perfusion, and metabolism in patients with advanced coronary artery disease undergoing surgical revascularization. Circulation 1994;90:2356-66 .

12. Dreyfus G, Duboc D, Blasco A, et al. Myocardial viability assessment in ischaemic cardiomyopathy: benefits of coronary revascularisation. Ann Thorac Surg 1994;57:1402-8.

13. Cohn J, Rector T. Prognosis of congestive heart failure and predictors of mortality. Am J Cardiol 1988;62(Suppl):25A$30 \mathrm{~A}$.

14. Wasserman K, Whipp B, Koyal S, Beaver W. Anaerobic threshold and respiratory gas exchange during exercise J Appl Physiol 1973;35:236-43.

15. Segar D, Brown S, Sawada S, Ryan T, Feigenbaum H. Dobutamine stress echocardiography: correlation with coronary lesion severity as determined by quantitative angiography. J Am Coll Cardiol 1992;19:1197-202.

16. Marinho N, Keogh B, Costa D, Lammertsma A, Ell P, Camici PG. Pathophysiology of chronic left ventricular dysfunction: new insights from the measurement of absolute myocardial blood flow and glucose utilisation. Circulation 1996;93:737-44

17. Fath-Ordoubadi F, Marinho N, Keogh B, Pagano D, Costa D, Camici PG. Value of positron emission tomography in predicting functional recovery following coronary revascularisation: effect of baseline wall motion score and ejection fraction [abstract]. Eur Heart J 1995;16(suppl):129.

18. Bland M, Altman D. Statistical methods for assessing agreement between two methods of clinical measurements. Lancet 1986;1(Feb 8):307-10.

19. Rector T, Spencer H, Cohn J. Validity of the Minnesota Living with Heart Failure Questionnaire as a measure of therapeutic response to enalapril or placebo. Am J Cardiol 1993;71:1106-7.

20. Metz C. Basic principles of ROC analysis. Semin Nucl Med 1978;8:283-98.

21. Wechsler AS, Junod FL. Coronary bypass grafting in patients 
with chronic congestive heart failure. Circulation 1989; 79(suppl I):I-92-6.

22. Luciani GB, Faggian G, Razzolini R, Livi U, Bortolotti U, Mazzucco A. Severe ischaemic left ventricular failure: coronary operation or heart transplantation? Ann Thorac Surg 1993;55:719-23.

23. Mickleborough L, Maruyama H, Tagaki T, Mohamed S, Sun Z, Ebisuzaki L. Results of revascularisation in patients with severe left ventricular dysfunction. Circulation 1995;92[suppl II]:ii-73-9.

24. Rosen S, Nihoyannopoulos P, Tousoulis D, Frackowiack R, Frith C, Jones T, et al. Silent ischaemia as a central problem: regional brain activation compared in silent and painful myocardial ischaemia. Ann Intern Med 1996;124:939-49.

25. Bonow R. Identification of viable myocardium. Circulation 1996;94:2674-8.

26. Ausma J, Cleutjens J, Thoné F, Flameng W, Ramaekers F,
Borges M. Chronic hibernating myocardium: interstitial changes. Mol Cell Biochem 1995;147:35-42.

27. Vanovershelde J, Melin J, Depré C, Borges M, Dion R, Wijns W. Time course of functional recovery of hibernating myocardium after coronary revascularisation [abstract]. Circulation 1994;90(Suppl):I378.

28. Armstrong W. "Hibernating" myocardium: asleep or part dead? J Am Coll Cardiol 1996;28:530-5.

29. Kaul S, There may be more viability than meets the eye! Circulation 1995;92:2790-3.

30. Franciosa J, Park M, Levine B. Lack of correlation between exercise capacity and indices of resting left ventricular performance in heart failure. Am J Cardiol 1981;47:33-9.

31. Townend J, Pagano D, Allen S, Jordan P, Davies M, Littler $\mathrm{W}$, et al. Results of surgical revascularisation in ischaemic heart failure without angina. Eur J Cardiothorac Surg 1995; 9:507-14. 